\title{
IMPLICACIONES ÉTICO-JURÍDICAS DE LA EDICIÓN DE GENES
}

\author{
ETHICAL AND LEGAL IMPLICATIONS OF GENE EDITING
}

\author{
Aliuska Duardo Sánchez ${ }^{1}$ \\ Universidad del País Vasco (UPV/EHU) \\ Ekain Payán Ellacuria ${ }^{2}$ \\ Universidad del País Vasco (UPV/EHU)
}

\begin{abstract}
Resumen:
El presente trabajo tiene por objeto abordar, desde las áreas de la Ética y el Derecho, el alcance de una de las biotecnologías que más impacto está generando en la literatura ante su potencial aplicación clínica. Ello obedece a las infinitas posibilidades que promete la edición de genes, y, más concretamente, su afamada herramienta CRISPR/Cas9, entre las que destaca la reparación de enfermedades graves en células germinales humanas, pudiendo evitar su eventual transmisión a los descendientes. No obstante, podría, como titula acertadamente una de las múltiples obras coordinadas y co-redactadas por nuestro maestro, el Profesor Romeo Casabona, ir "más allá de la salud", dando lugar a reminiscencias eugenésicas, y que vendrían representadas por medio de la mejora humana. Consecuentemente, se analizará, por un lado, la aceptabilidad desde el punto de vista ético de la terapia génica frente a la mejora, en ponderación con los principios bioéticos de autonomía, beneficencia, no maleficencia y justicia; y, por otro, la afectación que para los derechos fundamentales pudiera suponer su uso indiscriminado, muy especialmente, en cuanto a la dignidad humana, igualdad e identidad, así como al patrimonio genético inalterado y las responsabilidades para con las generaciones futuras, y de los que el Profesor Romeo ha sido pionero en alertar.
\end{abstract}

Palabras clave:

CRISPR/Cas9. Edición genética germinal. Mejora humana. Terapia génica.

\begin{abstract}
:
The aim of this paper is to address, from the areas of Ethics and Law, the scope of one of the biotechnologies that is generating most impact in the doctrine due to its potential clinical application. This is due to the infinite possibilities promised by gene editing, and more specifically, its famous tool: CRISPR/Cas9. Among its possible applications are the repair of serious diseases in human germinal cells, preventing their eventual transmission to descendants. However, it could, as one of the many works coordinated and co-written by our mentor, Professor Romeo Casabona, rightly calls it, go "beyond health", giving rise to eugenic reminiscences, which would be represented by human enhancement. Consequently, we will analyse, on the one hand, the ethical acceptability of gene therapy in the face of improvement, in consideration of the bioethical principles of autonomy, beneficence, non-maleficence and justice. On the other, will think in the effect that gene editing indiscriminate use could have on fundamental rights, especially in terms of human dignity, equality and identity, as well as on the unaltered genetic heritage and the responsibilities towards future generations, which Professor Romeo has been a pioneer in envisaging.
\end{abstract}

Key Words:

CRISPR/Cas9. Germinal gene editing. Human enhancement. Gene therapy.

\footnotetext{
${ }^{1}$ Investigadora Postdoctoral Juan de la Cierva. Dra. en Informática Aplicada al Derecho Universidade Da Coruña. Departamento de Derecho Público, Universidad del País Vasco UPV/EHU. Orcid: https://orcid.org/0000-00031504-9053.

${ }^{2}$ Investigador Predoctoral FPI. Departamento de Derecho Público, Universidad del País Vasco UPV/EHU. Al autor le gustaría aprovechar esta oportunidad para agradecer el apoyo a la Convocatoria de Contratación para la Formación de Personal Investigador en la UPV/EHU (2016), promovida por el Vicerrectorado de Investigación de la UPV/EHU, en la realización de este trabajo. Orcid: https://orcid.org/0000-0002-4681-8444.
} 


\section{INTRODUCCIÓN}

Los incesantes avances en los campos de la biomedicina (Gracia Guillén, 2011, pp. 209227) y, en particular, la biotecnología humana vienen centrando, muy por encima de las aplicaciones en animales, hongos y plantas, la práctica totalidad del interés científico. Entre ellos brillan con luz propia técnicas como la biología sintética o la edición de genes, que se examinará detalladamente en lo sucesivo, y que a partir de la adhesión de la nucleasa Cas9 por los equipos de investigación liderados por las recientemente proclamadas Premios Nobel de Química 2020, Doudna y Charpentier (Jinek et. al., 2012), no ha hecho sino aumentar exponencialmente la producción de publicaciones y búsquedas relacionadas con la misma (Duardo Sánchez, 2017, p. 1.). La cuestión no es baladí: y es que estas tijeras moleculares abren la puerta a realizar, sirviéndose de una ARN guía, incisiones específicas en regiones de ADN de forma más económica, eficiente y precisa que otros editores genéticos como TALEN y ZFN (Montoliu, 2019: 135), añadiendo, eliminando, modificando, reordenando o sustituyendo información genética que será posteriormente reparada -aunque de forma aleatoria y todavía desconocida- por el propio entramado celular del organismo vivo.

No obstante, sus bases fueron sentadas previamente en los Países Bajos, Japón y, sobre todo, en España, donde el microbiólogo Mojica descubrió hace más de dos décadas (Lander, 2016) la repetición de unas secuencias en el ADN de algunas bacterias y arqueas, que actuaban como una suerte de sistema de defensa inmunológico frente a ataques víricos al permitir identificarlos e incorporarlos a su propia dotación genética, y que bautizó como Repeticiones Palindrómicas Cortas Agrupadas y Regularmente Interespaciadas (más conocidas bajo el acrónimo CRISPR).

Desde entonces, y una vez constatada en 2013 la posibilidad real de intervenir en el genoma humano, no han dejado de sucederse los experimentos orientados a su aplicación clínica. Estos pueden acometerse en línea somática, es decir, en las propias células del individuo, por lo que sus consecuencias se extinguirían con su fallecimiento -si bien no se puede descartar que puedan alcanzar a las células germinales (Romeo Casabona, 2002a: 107), como ocurre con la radio y quimioterapia, tal y como reconoce expresamente el art. 92 del Informe Explicativo del Convenio de Oviedo, IECDHB-. Sin embargo, es la terapia génica germinal la que más interés suscita, pues, a diferencia de la anterior, se produce en las células reproductivas, razón por la que aspira a evitar la herencia intergeneracional de enfermedades incompatibles con la vida humana, habiéndose producido ya en embriones humanos para erradicar el VIH (Kang et. al., 2016). 
Es precisamente -y junto a EE. UU.- China uno de los países más activos en estas lides, quien sorprendió al mundo al anunciar en la Segunda Cumbre International sobre Edición de Genes el nacimiento de los dos primeros seres humanos editados genéticamente (Regalado, 2018) al objeto de prevenir -que no curar- la adquisición de este retrovirus, del que uno de sus progenitores era portador, aumentando su resistencia a través de la inactivación del gen CCR5. Ello le valió al Dr. He Jiankui una unánime reprobación internacional que concluyó con la determinación de su responsabilidad penal, pues, además de incumplir los estándares académicos, obvió la falta de seguridad científica de la que adolece CRISPR-Cas9 y que la sigue haciendo, hoy por hoy, inviable: efectos secundarios, mosaicisimo y mutaciones espontáneas o fuera del objetivo, entre otros, que, en este caso, podrán padecer no solo las gemelas, condenándolas a una vida de control médico y seguimiento permanente, sino su futura progenie. A su vez, no puede confirmarse que los progenitores dispusieran de una composición plena acerca del alcance del acto consentido (Romeo Casabona, 2002b, 84). En virtud de lo anterior, varios autores se han apresurado en solicitar una moratoria para su uso germinal (Lander et. al., 2019), reproduciendo así la posición que ya manifestaron algunos miembros del Grupo Europeo de Ética de la Ciencia y las Nuevas Tecnologías - del que es miembro el Profesor Romeo- en su Declaración sobre edición genética (European Group on Ethics in Science and New Technologies, 2016, p. 2).

Pese a que los riesgos científicos constituyen el principal obstáculo para la validación de la edición genética, el suceso acontecido ha puesto de manifiesto la conveniencia de analizar, por un lado, los dilemas éticos y, por otro, los derechos susceptibles de protección (Romeo Casabona, 2002a, p. 17 y ss.) ante lo que supone, con toda probabilidad, uno de los más firmes desafíos a los que se enfrenta la humanidad.

\section{DICOTOMÍA TERAPIA/MEJORA}

Antes de realizar esta inmersión, es preciso identificar los fines de la edición de genes $\mathrm{y}$, aunque con mayor dificultad, tratar de establecer sus límites, pues en función de ellos pivotará tanto su admisibilidad desde el punto de vista de la ética como la interpretación que, en su caso, quepa hacer acerca de la legislación en vigor.

Como primera premisa, debe partirse de la vinculación entre terapia y tratamiento, encaminándose a la curación de determinadas enfermedades o lesiones (Morán González, 2012, p. 2). Por el contrario, la mejora humana tendería a superar el estado normal (Canguilhem, 1986, p. 92) y no patológico de salud. Siguiendo al Profesor Romeo: 


\begin{abstract}
Por mejora (enhancement) pueden entenderse las técnicas o procedimientos de mejora, perfeccionamiento o fortalecimiento, de forma permanente o temporal, de algunas características, capacidades o habilidades corporales, psico-mentales o intelectuales del ser humano nacido o por nacer, o de control de ciertos procesos biológicos, por lo general limitantes. (Romeo Casabona, 2013, p. 162)
\end{abstract}

A pesar de que, desde un planteamiento teórico, y teniendo el carácter curativo como límite, las diferencias entre ambas categorías no parezcan entrañar mayor dificultad, lo cierto es que, en la práctica, dista mucho de ser así. Por un lado, la existencia de otras clasificaciones, como la prevención y el diseño genético, amplían el espectro donde pueda situarse un caso concreto. Sirva como ejemplo el ya citado de las niñas editadas genéticamente, que puede ser considerado tanto preventivo como meliorativo -si bien es cierto que predomina esta última opinión, que sostiene, entre otros, el Comité de Bioética de España (Comité de Bioética de España, 2019, p. 2) ${ }^{3}$. Más aún, pueden cohabitar zonas grises, integradas por características pertenecientes a cada una de ellas, como la "mejora terapéutica” (Navarro Navas y Camacho Clavijo, 2018, p. 9). Por cuanto antecede, no puede concluirse que se trate de compartimentos estancos, sino que pueden estar correlacionados. Por otro, la consideración de enfermedad tiene un componente ciertamente subjetivo, pues esta puede variar en función de valoraciones familiares, históricas o socioculturales. Es el paradigmático caso de Sharon Duchesneau y Candace McCullough, quienes padecían sordera y decidieron deliberadamente -no sin polémica y dudosa fundamentación, por cuanto podría haber sido constitutivo de un delito de lesiones al feto-que su descendencia heredara esta condición por considerarla no solo expresiva de su grupo social, sino favorecedora en pos de su educación e integración en el mismo (Rodrigues, 2016, pp. 130-133).

Lo mismo cabe argüir en cuanto a la consideración de su mayor o menor gravedad. De ahí que, siguiendo la propuesta de elaborar un listado de enfermedades que puedan ser objeto de terapia génica en línea germinal (Romeo Casabona, 1994a, 193), las Academias Nacionales de Ciencias, Ingeniería y Medicina se hayan decidido a publicar en su último informe unas vías de actuación responsable que, además de criterios tasados, y por cuanto aquí interesa, recogen dos categorías de enfermedades en los que se podrían amparar los usos iniciales de la edición genética germinal -al menos, hasta que las investigaciones en curso y que se desarrollen ulteriormente permitan obtener un mayor nivel de seguridad-. El primero estaría compuesto por aquellas enfermedades monogénicas graves en las que todos los niños

\footnotetext{
${ }^{3}$ Comité, por cierto, del que el Profesor Romeo fue miembro hasta 2018, cuando agotó su período de pertenencia.
} 
heredarían el genotipo deletéreo. Aunque enumera la anemia falciforme, beta-talasemia, Huntington y fibrosis quística, estas condiciones dominantes son coincidentes con otra que presenta una esperanza de vida limitada y un elevado sufrimiento, como Tay-Sachs, y que podría, por la idéntica severidad de estos padecimientos, considerarse susceptible de inclusión. El segundo se refiere a enfermedades monogénicas graves en las que algunos -pero no todoslos hijos de una pareja lo padecerían, lo cual admitiría excepcionalmente bajo dos condiciones: que la expectativa de éxito de tener descendencia sana y biológicamente relacionada sea del $25 \%$ o inferior, y que se los progenitores se hayan sometido necesariamente, antes de acudir a la edición de genes, a Diagnóstico Genético Preimplantatorio (DGP) ${ }^{4}$ (National Academy of Medicine, National Academy of Sciences, and The Royal Society, 2020: 109-110). Todos los demás supuestos quedarían, a juicio de las Academias, excluidos por diferentes motivos, entre los que sobresalen la existencia de alternativas más seguras y el desconocimiento acerca de las interacciones que la edición de genes pudiera provocar. Este listado aporta cierta certidumbre y seguridad jurídica, si bien para dotarlo de legitimación y alcance internacional, ha de ser consensuado y sometido a constante revisión, así como, en su caso, actualización ${ }^{5}$.

\section{PERSPECTIVAS BIOÉTICAS}

Aunque una parte de la ética se opone a la edición genética germinal por significar el tratamiento de un paciente todavía inexistente y, por ende, que no reviste carácter urgente (Baylis, 2019, p. 80), prima facie, no parece reprochable moralmente la curación o prevención de enfermedades graves detectadas, cuando estas pueden derivar en un prematuro y traumático fallecimiento. Esta es la línea que han secundado los Comités Consultivo Nacional de Ética en Ciencias de la Vida y Salud francés, el Consejo de Bioética de Nuffield británico y el Consejo de Ética Alemán en su reciente informe conjunto, al considerar concebibles “(...) casos en los que la aplicación clínica de la edición del genoma hereditaria podría ser moralmente permisible. Por tanto, no consideramos que la línea germinal humana sea categóricamente inviolable” (Comité Consultatif National d’Éthique pour les sciences de la vie et de la santé, Nuffield Council on Bioethics and Deutscher Ethikrat, 2020, p. 3). Ahora bien, esta afirmación -no categórica, sino que apunta a admitirse casuística y excepcionalmente-

\footnotetext{
${ }^{4}$ Técnica de reproducción asistida por la que es posible la selección in vitro de embriones sanos, procediendo a su implantación en el útero, y desechando los patológicos o destinándolos a fines de investigación.

${ }^{5}$ Para ello, podría ser procedente el establecimiento de un mecanismo análogo al del art. 28 del Convenio del Consejo de Europa para la protección de los derechos humanos y la dignidad del ser humano respecto de las aplicaciones de la biología y la medicina (CDHB), contemplándose un proceso periódico de consultas.
} 
debe ser coherente con los principios bioéticos de autonomía, no maleficencia, beneficencia y justicia (Romeo Casabona, 2017, 6). Más concretamente, deben ponderarse los riesgos y beneficios, pudiendo aplicarse solo en caso de que los segundos sean superiores a los primeros. Asimismo, debe acreditarse la ausencia de alternativas razonables, como podría constituir, por ejemplo, el DGP para enfermedades graves no recesivas, si bien, por un lado, la consideración del embrión humano como ser merecedor de dignidad (Bellver Capella, 2016, 235) -aun cuando las Sentencias del Tribunal Constitucional español 53/1985, de 11 de abril; 212/1996, de 19 de diciembre; y 116/1999, de 17 de junio, no le reconozcan como titular de derechos fundamentales, no obstando ello a su perspectiva gradualista y potencialista (Romeo Casabona, 2004a, p. 115)-; y, por otro, las convicciones religiosas de los progenitores pueden erigirse en fuente de divergencia ética. Finalmente, no deben procurarse daños a terceros, teniendo presente que siempre existe un mínimo riesgo en cualquier intervención de origen médico. Coincidimos, a este respecto, con la posición del Profesor Romeo, quien supedita la eticidad de los futuros usos de la técnica a la previa superación de efectos adversos:

(...), cuando se conozca mejor y se domine esta técnica, pudiendo descartarse sus efectos secundarios perniciosos, habrá que pensar en levantar estas prohibiciones, estableciendo al mismo tiempo unos criterios conforme a los cuales sea admisible esta forma de tratamiento y puedan controlarse al mismo tiempo otros usos indebidos. (Romeo Casabona, 2009, p. 119)

Empero, la revolución de las técnicas de reproducción asistida e ingeniería genética, respectivamente, ha reavivado la sombra de la eugenesia (Buchanan, Brock, Daniels y Wikler, 2002, p. 9). A este respecto, y si bien es difícilmente escindible el estigma histórico aparejado a este concepto fruto de la desgarradora experiencia que asoló al mundo en la primera mitad del siglo XX, conviene detenerse en sus elementos integradores a fin de verificar o no su pervivencia. Así, mientras la eugenesia tradicional se caracterizaba por la coacción con la que era ejercida por Estados de corte totalitaria, bajo la que subyacían motivaciones discriminatorias, clasistas o racistas amparadas en el determinismo genético, la actual se diferencia por la capacidad decisoria los progenitores, su finalidad preventiva o terapéutica y el conocimiento, particularmente, en cuanto a los efectos alimentarios, ambientales, culturales o de estilo de vida -epigenética- y su área de influencia en las interacciones genéticas que se traducen en un polimorfismo genético. Es por ello que ya en 1997 el Profesor Romeo acuñó el termino “neoeugenesia”, que aúna, con mayor rigor, las diferencias entre ambas acepciones: 
Revista da Faculdade Mineira de Direito | V.23 N.46|

Dossiê "O Direito e a Bioética ante os limites da Vida Humana em Carlos María Romeo Casabona"

A diferencia de los movimientos eugenésicos de principios de siglo que propugnaban una mejora de la raza y la protección de la especie y se orientaban hacia los efectos sociales inmediatos de las prácticas de eugenesia, (...) la nueva eugenesia está planteada por el momento como una cuestión médica, propia de la esfera de la relación médico-paciente y, por ello, como un asunto de salud individual; de salud de los propios interesados y de las generaciones futuras, acreedoras de un derecho a la salud -a nacer sanos- frente a sus progenitores y sus facultades o libertades reproductivas. (Romeo Casabona, 1997, p. 111)

Sentado lo anterior, la mera alusión al término eugenesia advirtiendo sobre el riesgo de su retorno no constituiría un argumento ético de suficiente entidad, sino que, más bien al contrario, vendría justificado por razones de planificación familiar:

Quedarían fuera de la problemática eugenésica en su sentido tradicional aquéllas que pretenden garantizar tener una descendencia sana -esto es, con fines preventivos, eliminando los riesgos de transmisión de enfermedades hereditarias, de las que serían portadores por tanto los padres, y que son fruto de la libre decisión de estos con el concurso del asesoramiento genético por parte del médico (eugenesia terapéutica), por lo que la pretensión de asegurarse una descendencia sana o libre de patologías o malformaciones hereditarias no tiene en cuanto tal nada de censurable; por supuesto, tampoco desde un punto de vista eugenésico. (Romeo Casabona, 2002a, pp. 138-139)

Algunos autores de la escuela anglosajona han superado esta idea, enarbolando el principio de beneficencia procreativa (Savulescu y Kahane, 2009, p. 274) y por el que los padres prospectivos tendrían no solo el derecho, sino la "obligación moral” de tener los hijos cuyas vidas se espera que sean las mejores. No obstante, la indeterminación y subjetividad de este imperativo puede llevar a los progenitores a adoptar elecciones instrumentales que poco o nada tengan que ver con las propias de la salud, dando lugar a otra categoría que - esta vez sí- podría identificarse como propiamente eugenésica: la mejora de la raza humana.

(...) el gran potencial eugenésico (ahora de eugenesia positiva: seleccionar determinados rasgos fenotípicos) que ofrecen las investigaciones sobre el genoma humano, con métodos que se vislumbran de extraordinaria precisión, aunque también de particular complejidad a corto plazo, son (...) las intervenciones en el genoma, en concreto en el de las células germinales (los gametos) y el embrión en los primeros estadios de su división celular (en su fase de totipotencialidad), justo también al hilo de la terapia génica en la línea germinal. Precisamente de ésta última rebrota el importante interrogante, de fondo filosófico, de la distinción entre lo normal y lo patológico, entre éste, lo diferente y lo infrecuente, como premisa para reconocer los inmensos beneficios que reportará la terapia génica, pero también el riesgo eugenésico, por lo que debe ser ampliamente debatido. (Romeo Casabona, 1999a: 128)

La defensa ética de los fines meliorativos o perfectivos resulta mucho más controvertida, tal y como lo atestiguan las declaraciones internacionales (Max Planck Society, 2019, p. 3), pues no se trata de bienes absolutos como la salud, sino comparativos o posicionales 
-como podrían ser la altura o la memoria-, lo que, si se llegaran a dominar las combinaciones poligénicas, conllevaría aminorar, irreductible e indirectamente, los del resto de la población.

A juicio de aquellos autores etiquetados como "bioconservadores”, se estaría cruzando una línea al alterar el orden natural establecido, ocupando un lugar que solo corresponde a Dios en calidad de creador (Habermas, 2003, p. 21). A sensu contrario, el argumento de la sacralidad del genoma humano podría tener difícil encaje con el art. 3 de la Declaración Universal sobre el Genoma Humano y los Derechos Humanos (DUGHDH), 11 de noviembre de 1997, cuando reconoce la naturaleza evolutiva del genoma humano y su sometimiento a mutaciones. Ello no hace sino refutar los cambios aleatorios y constantes que acontecen generación tras generación, y que solo podrían evitarse a través de la clonación reproductiva -práctica no permitida por el art. 11 DUGHDH- o, más aún, la edición genética (de Miguel Beriain, 2018, p. 2). Adicionalmente, cabe atender a la humildad, responsabilidad y solidaridad, virtudes que podrían verse seriamente desdibujadas por influjo de las bioingenierías (Sandel, 2015, p. 15 y 140).

Otra de las metáforas más recurrentes es la de la pendiente resbaladiza, en base a la que, aun cuando la finalidad inicial de la terapia génica sea curativa, su uso puede llevar a la sociedad a banalizar las consecuencias de las intervenciones genéticas, deslizándose, lenta y progresivamente, hacia la aceptación de cotas éticamente cuestionables como la mejora. Este postulado eminentemente predictivo ha sido criticado por algunos autores (de Miguel Beriain, 2019, pp. 72-73), condicionándose su legitimidad a que se exhiba un relato fáctico claro y debidamente individualizado que evite una inversión de la carga probatoria, lo que, aun siendo plausible, no está exento de dificultades (van der Burg, 1991, p. 61).

Es en este contexto donde cobran especial protagonismo sendos principios de actuación: por un lado, el de responsabilidad (Jonas, 1997, p. 40); y, por otro el de precaución, de naturaleza ética y jurídica, que precisa para su aplicación tanto de una situación de incertidumbre científica como de eventuales daños graves e irreversibles (Romeo Casabona y de Miguel Beriain, 2010, p. 191). Se plantea, a este respecto, la convergencia de ambas premisas en materia de edición de genes:

Una consecuencia lógica del principio de precaución es la necesidad de adoptar medidas orientadas a prevenir riesgos de daños especialmente graves. Es decir, se debe actuar adoptando medidas de protección con anterioridad a que aparezca el daño, incluso aunque no exista una evidencia científica completamente comprobada sobre la nocividad de una actividad o de un producto. (Romeo Casabona, 2004b, p. 392) 
Ha quedado patente con anterioridad que la Ciencia no se encuentra en situación de garantizar su inocuidad, no pudiendo garantizarse que los efectos perniciosos que se generen sean de igual o mayor significación que los que se pretendan evitar (Maier, Akbari, Wei, Patterson, Nielsen y Reich, 2019). Y todo ello dejando de lado los riesgos que para la bioseguridad o biodiversidad puedan suponer diferentes manifestaciones de la ingeniería genética, entre las que se encuentra la producción de armas biológicas (de la Cuesta Arzamendi, 2001, p. 240; Romeo Casabona, 2009, p. 343 y ss.). Parece, pues, que su concurso podría ser razonable a la luz de los antedichos requisitos y, de la misma manera, con las solicitudes de moratoria registradas hasta la fecha:

\footnotetext{
La terapia génica en la línea germinal, al no estar vinculada al tratamiento de una enfermedad grave para el afectado sino a su capacidad de tener hijos sanos, y al no conocerse sus efectos colaterales y en la propia herencia, debe someterse a una moratoria cuando sea posible su aplicación al ser humano (Romeo Casabona, 1994b, p. 33)
}

Sentada la excepcionalidad que podría motivar esta decisión, ello no debería resultar una rémora para el ejercicio de la libertad de investigación -reconocida en los arts. 15 CDHB, 12 b) DUGHDH y como derecho fundamental a la creación y la producción científicas en el art. 20.1 b) de la Constitución Española (CE) de 1978-, toda vez que cautela no significa prohibición (National Academies of Sciences, Engineering and Medicine, 2017, p. 134). Tampoco debe ignorarse la proliferación de mercados negros y biohackers, que, sin necesidad de proveerse de gran infraestructura (Romeo Casabona, 2007, p. 14), pueden comercializar y desarrollar kits de CRISPR-Cas9, incluso, con la connivencia de países con regulaciones laxas, promoviendo paraísos genéticos. En suma, la investigación en ciencia básica ha demostrado ser no solo compatible, sino necesaria para acometer hallazgos tan importantes como los antibióticos o la fecundación in vitro, por lo que debe ser espoleada siempre que pueda redundar en el beneficio de toda la humanidad -máxime en tiempos de COVID-19, en el que se escriben estas líneas.

\section{LA INTANGIBILIDAD DE LOS DERECHOS}

Los efectos transnacionales que las Ciencias Biomédicas pueden representar para el Derecho han dado lugar a que la normativa internacional se haya ocupado, ya desde el siglo pasado, de su positivización. Sin embargo, se ha puesto de manifiesto que las tecnologías de edición genética son novedosas y disruptivas -al menos, en cuanto a su aplicación clínica 
vía CRISPR-Cas9-, lo que explica que las referencias de los textos legales en vigor no sean profusas, y que, siguiendo la estela del art. 32.4 CDHB, pudiera ser plausible su renovación.

El único texto que cita expresamente el término eugenesia es la Carta de Derechos Fundamentales de la Unión Europea (CDFUE, 2000/C 364/01) cuando prohíbe, en su art. 3.2, este tipo de prácticas, haciendo especial énfasis en aquellas encaminadas a la selección de las personas. Podría, no obstante, hallarse una excepción a este último punto, toda vez que el art. 14 CDHB ampara la elección del sexo cuando ello sea preciso para evitar una enfermedad hereditaria grave vinculada al género -aunque no aclara si el embrión debe padecerla, si basta con ser portador de la patología o si se permite ayudar a un hermano como donante-. Asimismo, se infiere, a sensu contrario, la selección del sexo o manipulación genética con fines terapéuticos autorizados entre las infracciones muy graves del art. 26.2.c)

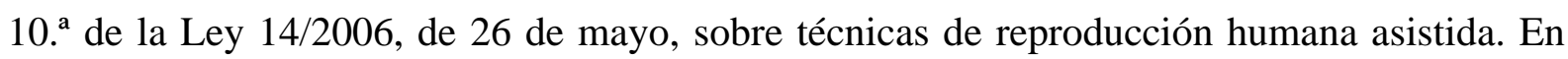
cualquier caso, para su interpretación habrá que estar, nuevamente, a la noción contemporánea de eugenesia.

A la CDFUE hay que adicionar otras dos normas comunitarias: una, la Directiva 98/44/CE del Parlamento Europeo y del Consejo, de 6 de julio de 1998, relativa a la protección jurídica de las invenciones biotecnológicas, que veta en su art. 6.2 b) la patentabilidad de los procedimientos de modificación de la identidad genética germinal del ser humano; y dos, el Reglamento (UE) No. 536/2014 del Parlamento Europeo y del Consejo, de 16 de abril de 2014, sobre los ensayos clínicos de medicamentos de uso humano, y por el que se deroga la Directiva 2001/20/EC del Parlamento Europeo y del Consejo, de 4 de abril de 2001, relativa a la aproximación de las disposiciones legales, reglamentarias y administrativas de los Estados miembros sobre la aplicación de buenas prácticas clínicas en la realización de ensayos clínicos de medicamentos de uso humano, en cuyo art. 90 se impiden los ensayos clínicos de terapia génica que produzcan modificaciones en la identidad genética germinal del sujeto. Estas disposiciones fueron transpuestas un año después en el ordenamiento jurídico español: en concreto, la primera en el art. 5.1 b) de la Ley 24/2015, de 24 de julio, de Patentes; y la segunda en el art. 17.3 del Real Decreto 1090/2015, de 4 de diciembre, por el que se regulan los ensayos clínicos con medicamentos, los Comités de Ética de la Investigación con medicamentos y el Registro Español de Estudios Clínicos, prohibiendo, igualmente, los ensayos clínicos con medicamentos de terapia génica cuando impliquen la alteración de la identidad génica de la línea germinal de la persona.

Como puede colegirse, estos textos coinciden en otorgar protección a la identidad genética del ser humano, lo que da buena muestra de la relevancia que comporta este bien 
jurídico para el legislador. En todo caso, no debe equipararse a la identidad personal, pues mientras que la primera se ha asociado fundamentalmente con la clonación (Romeo Casabona, 2000a, p. 149), la segunda está compuesta por una multiplicidad de factores que exceden, como se verá, de la mera genética (Romeo Casabona, 2000a, p. 151).

Mayor atención presta el articulado del CDHB a la derechos y libertades emanados de las aplicaciones biológico-médicas. Este Convenio marco del Consejo de Europa es vinculante para aquellos Estados signatarios que lo han ratificado, entre los que se encuentra el Reino de España, si bien cuenta con destacadas ausencias (entre otras, y por razones contrapuestas sobre su ideal restrictivo o aperturista, Alemania, Bélgica y Reino Unido).

Así, destaca sobremanera el manido art. 13 CDHB, relativo a las intervenciones sobre el genoma humano, que solo podrá efectuarse de concurrir dos supuestos:

1. Cuando tenga por objeto modificar el genoma humano por razones preventivas, diagnósticas o terapéuticas.

2. Solo cuando no tenga por finalidad la introducción de una modificación en el genoma de la descendencia.

Aun cuando estos criterios podrían reunirse en línea somática -art. 90 IECDHB-, existe consenso doctrinal mayoritario en que la terapia génica germinal implicaría modificar el patrimonio genético de la descendencia, independientemente de que el propósito para ello fuera curativo, lo que no se exceptúa (Romeo Casabona, 1999b, p. 53). De ahí que se haya propugnado no solo la protección del derecho a la vida y a la integridad física y moral -art. 15 CE-, sino un bien jurídico de entidad supraindividual: el derecho a un patrimonio genético no patológico -art. 1 DUGHDH (Romeo Casabona, 2002c, pp. 293-294)- o, sintetizado, a la integridad genética, cuya esencia radica en la inalterabilidad de las características inherentes a la especie humana (Romeo Casabona, 1994b, p. 370), fuente de diversidad biológica, y que la edición genética podría comprometer:

El interés por la protección de la especie no ha decrecido, pero ahora se presenta desde una óptica diametralmente opuesta: mientras que los avances de la Biología de la segunda mitad del siglo XIX y de principios del XX ayudaron a conocer la evolución de la especie humana y a que algunos llegaran a predecir el peligro de su devenir (por haber interferido el ser humano en los procesos de selección natural, etc.) y a concluir la necesidad de atajar el peligro con los procedimientos expuestos, los más precisos conocimientos actuales suscitan la preocupación de mantener inalterada la identidad e integridad biológica de la especie, de proteger el genoma humano de manipulaciones y considerarlo patrimonio de la humanidad (Romeo Casabona, 2002a, p. 145) 
La falta de concreción del art. 13 CDHB faculta, en todo caso, que se realicen interpretaciones alternativas en virtud de las cuales pudiera llegar a considerarse loable la edición genética del genotipo (Emaldi Cirión, 2002, pp. 210-211; de Miguel Beriain y Payán Ellacuria, 2019, p. 86), habida cuenta, además, de la primacía de la que goza el interés del ser humano frente a la Ciencia o la sociedad-art. 2 CDHB y art. 3.2 de la Declaración Universal sobre Bioética y Derechos Humanos (DUBDH), de 19 de octubre de 2005-, por ejemplo, cuando de evitar una enfermedad genética se trate.

Directamente relacionada con esta primacía se encuentra la protección de la dignidad humana. Su ubicación sistemática a modo de artículo primero tanto en la CDHB como en la CDFUE denota su incontestable valor; junto con los anteriores, se configura en el art. 2 DUGHDH y 3.1 DUBDH y, finalmente, a escala nacional en el art. 10.1 CE como principio informador que se proyecta jurídicamente sobre los derechos fundamentales. Forma parte importante, pues, de los más significativos textos internacionales y nacionales de derechos, a los que sirve de sustento. A pesar de que no existe una definición pacífica de dignidad -lo que ha servido para que sea empleada de forma ambivalente por partidarios y detractores de la edición de genes (Romeo Casabona, 1999a, 134-, puede convenirse en que es intrínseca a todos los seres humanos por el hecho de serlo, que, en su versión kantiana, se conciben como fines en sí mismos, y no meros medios (European Group on Ethics in Science and New Technologies, 2018, p. 16). La dignidad se concreta en la identidad personal que anticipábamos, derecho a la irrepetibilidad que se engarza en el art. 1 CDHB no solo en una esfera individual, sino colectiva (Romeo Casabona, 2000b, p. 34 y 37); paralelamente, se recoge en el art. 8 de la Convención sobre los Derechos del Niño (CDN), de 20 de noviembre de 1989. Formarían parte de esta identidad cualesquiera elementos civiles y registrales que posibilitan a la persona el libre desarrollo de su personalidad.

Otro de los derechos fundamentales que promociona el CDHB es el de igualdad -art. 3, en su vertiente de acceso equitativo a los progresos de la biología, la genética y la medicina en materia de genoma humano; en el mismo sentido, arts. 12 a) DUGHDH, 20 CDFUE, 10 DUBDH y 14 CE-, y no discriminación por características genéticas -arts. 11 CDHB, 6 DUGHDH, 21 CDFUE, 11 DUBDH, 14 CE y 6 de la Ley 14/2007, de 3 de julio, de Investigación Biomédica, LIB (Romeo Casabona, 2008)-. Efectivamente, es un riesgo latente que -si bien CRISPR-Cas9 presume de un bajo coste que sus adalides confían en que descienda aún más conforme se expanda su uso, tal y como ha ocurrido históricamente con otras muchas tecnologías-, no sea accesible por razones económicas para el conjunto de la población (Baylis, 2019, p. 112), especialmente en aquellos países que no disfruten de sistemas nacionales de salud 
públicos y sólidos. No debe obviarse, a este respecto, el art. 15 DUBDH, que mandata la distribución de los beneficios para con la sociedad y la Comunidad Internacional, subrayando la importancia que tiene para la justicia social materializar este compromiso con los países en desarrollo. Aunque es cierto que el acceso a la salud ya es desigual para muchas personas que no pueden permitirse determinados tratamientos, no sería descabellado que esta situación pudiera verse exacerbada, conduciendo a la marginalización de colectivos vulnerables (Baylis, 2019, pp. 104-105), lo que atentaría contra la protección que para ellos procura el art. 8 DUBDH. De consumarse esta polarización, podría traducirse, a grandes rasgos, en el germen de dos grupos sociales enfrentados: los seres humanos y los mejorados (de Miguel Beriain y Armaza Armaza, 2018, p. 193). Añade el art. 12 CDHB que las pruebas predictivas de enfermedades genéticas o que permitan identificar al sujeto como portador de un gen responsable de una enfermedad, o detectar una predisposición o susceptibilidad genética a una enfermedad, sólo responderán a fines médicos o de investigación en el marco de un consejo genético apropiado (Emaldi Cirión, 2001), advirtiendo el Profesor Romeo sobre el riesgo de que esta información sea indebidamente utilizada y distribuida, dando lugar a prácticas discriminatorias (Romeo Casabona, 2002d, pp. 166-169).

Antes de finalizar con la legislación internacional, debe traerse a colación un texto que ilustra vivamente la sensibilidad intergeneracional: nos referimos a la Declaración sobre las Responsabilidades de las Generaciones Actuales para con las Generaciones Futuras, de 12 de noviembre de 1997. Y ello es así por cuanto un uso negligente de la edición genética germinal podría condicionar el derecho a un futuro abierto que, como si de un libro en blanco se tratara, asiste a las generaciones subsiguientes (Buchanan, Brock, Daniels y Wikler, 2002, p. 301 y ss.). Como no puede ser de otra manera, los padres adoptan decisiones, por acción u omisión, que repercutirán en la formación biológica de su embrión incluso con antelación al momento de su concepción, pudiendo darse la casuística de que, en aquellos supuestos en los que la técnica esté disponible para su puesta en práctica y se haya producido el entero desprendimiento del seno materno ex art. 30 del Código Civil español, viole el interés superior del menor y, en fin, su derecho al disfrute del más alto nivel posible de salud reconocido tanto en el art. 12.1 del Pacto Internacional de Derechos Económicos, Sociales y Culturales, de 16 de diciembre de 1966, como en los arts. 3.1 y 24.1 CDN, lo que puede otorgar soporte a la interposición de acciones de responsabilidad civil en sede jurisdiccional con base en el art. 24 CDHB (Habermas, 2003, p. 13).

Con respecto al marco legal español, debe hacerse notar, por un lado, la distribución competencial a causa de una estructura autonómica descentralizada; y, por otro, la inexistencia 
de una ley integral sobre edición de genes, lo que abunda en su complejidad (Romeo Casabona, de Miguel Beriain y Duardo Sánchez, 2020, p. 390). Como muestra de ello, en un escalón jerárquico inferior al de la CE y al CDHB, se han señalado ya actos europeos que, de conformidad con lo dispuesto en el art. $96 \mathrm{CE}$, han sido integrados en nuestro ordenamiento jurídico. Junto a los anteriores coexisten leyes orgánicas y ordinarias que, sin hacer mención directa a la edición genética germinal, parecen vedarla al mantener el espíritu del art. 13 CDHB. Es el caso de la Ley Orgánica 10/1995, de 23 de noviembre, del Código Penal (CP), en cuyo Título V se tipifican los delitos relativos a la manipulación genética -sin que se haga referencia al bien jurídico protegido-, a los que destina los arts. 159, 160, 162 y, tangencialmente, 349 CP. La protección penal que otorgan estos preceptos -a pesar de la amplitud que supone establecer genéricamente como hecho típico la manipulación de genes humanos (Romeo Casabona, 1996a, pp. 463-464), con un tipo subjetivo doloso que difiere de fines terapéuticos, esto es, perfectivos, o imprudente grave, y que se consuma con la alteración del genotipo-, a la vista del actual estado del arte científico, adquiere un significado más allá de lo estrictamente simbólico que refuerza su pertinencia, aunque un sector de la doctrina se inclinara en el momento de su redacción por su ubicación sistemática en una ley penal especial para una mejor satisfacción de los fines de prevención general (Romeo Casabona, 1996b, pp. 166-167), y todo ello sin perjuicio de que se planteen dudas en torno a la conjugación de la libertad de investigación con los principios penales de intervención mínima y ultima ratio. También lo restringe el art. 13 de la Ley 14/2006, de 26 de mayo, sobre Técnicas de Reproducción Humana Asistida en cuanto a las intervenciones terapéuticas en el preembrión, y el art. 74.2 c) LIB, que establece en su capítulo de sanciones como infracción muy grave la realización de cualquier intervención dirigida a la introducción de una modificación en el genoma de la descendencia.

\section{CONSIDERACIONES FINALES}

A través de este artículo hemos tratado de hacer una aproximación a la edición genética desde las ópticas de la Ética y el Derecho, sirviéndonos para ello, por lo relevante de sus aportaciones, de la prolífica obra del Profesor Romeo. Las bondades que se esperan de CRISPRCas9 para poner coto a enfermedades aberrantes han supuesto un aumento sin parangón de estos experimentos en los últimos años, que auguran el resurgimiento de la carrera biotecnológica entre las principales potencias mundiales -a saber, Estados Unidos de América, China y Rusia-. Ello ha traído como consecuencia que la práctica totalidad del debate se haya centrado en la Ciencia y, en un plano subsidiario, la Bioética (Andorno et. al., 2020, p. 2), no 
reparándose suficientemente en la vigencia de los Derechos Humanos (DD. HH.) como punto de encuentro generador de consenso y límite infranqueable ante eventuales abusos o arbitrariedades que puedan producirse contra la especie humana:

\begin{abstract}
La comprobación de que los derechos humanos más elementales son vulnerados con excesiva frecuencia, tanto en las sociedades democráticas como -sobre todo- en las totalitarias de diferente signo, en las desarrolladas como en las que se encuentran en vías de desarrollo, no debe impedir ver que en el horizonte se proyecta una decidida voluntad colectiva de continuar avanzando en uno de los $<<$ descubrimientos $>>$ más importantes de la comunidad internacional: los derechos humanos. (...), no deja de ser cierto que son el mejor dique de protección del individuo no sólo frente al poder de los Estados sino también de otros poderes fácticos, que pueden sentir -o han sentido ya-la tentación de someter al individuo precisamente por medio del desarrollo científico y tecnológico (Romeo Casabona, 2002a, 57)
\end{abstract}

Para ello, ya existen mecanismos jurídicos disponibles (Romeo Casabona, 2013, p. 172), que se ven aderezados por la dimensión objetiva y dinámica que entroncan los DD. HH., pudiendo desarrollarse derechos o identificarse otros nuevos para la protección de bienes jurídicos incompletos o todavía inexplorados en caso de que sea menester (Romeo Casabona, 2002a, p. 13).

Por último, no debe desmerecerse el rol que ocupa la sociedad civil en este proceso deliberativo global junto al resto de agentes implicados, pues su opinión informada y participación proactiva resulta crucial para el camino que se decida emprender con la edición genética y el devenir que ello pueda significar para el futuro de la humanidad:

\footnotetext{
Antes bien, la gestión democrática del riesgo significa dar paso a la sociedad y sus formas de expresión a través de los movimientos sociales y ciudadanos, con el fin de lograr un verdadero proceso democrático de decisión y, en última instancia, lograr un equilibrio entre las diversas ópticas e intereses presentes en la comunidad (Romeo Casabona, 2004b, p. 387)
}

Las bases para no errar en el camino están, pues, sentadas. Y gran parte de ese trabajo debe reconocérsele al Profesor Romeo por su desinteresada y despierta labor académica, que, seguro, seguirá desempeñando con el rigor y tesón que le caracterizan. Sirva esta contribución para ponerlo de manifiesto y mostrarle nuestra admiración.

\title{
REFERENCIAS
}

ANDORNO, Roberto; BAYLIS, Françoise; DARNOVSKY, Marcy; DICKENSON, Donna; HAKER, Hille; HASSON, Katie; LOWTHORP, Leah; ANNAS, George J.; BOURGAIN, Catherine; DRABIAK, Katherine; GRAUMANN, Sigrid; GRÜBER, Katrin; KAISER, 
Matthias; KING, David; KOLLEK, Regine; MACKELLAR, Calum; NIE, Jing-Bao; OBASOGIE, Osagie K.; FANG, Mirriam Tyebally; WERNER-FELMAYER, Gabrielle; y ZUSCINOVA, Jana. 2020. "Geneva Statement on Heritable Human Genome Editing: The Need for Course Correction”. Trends in Biotechnology 4, 38: 1-4.

BAYLIS, Françoise. 2019. Altered Inheritance. CRISPR and the Ethics of Human Genome Editing. Cambridge, Massachusetts: Harvard University Press.

BELLVER CAPELLA, Vicente. 2016. “La revolución de la edición genética mediante CRISPR-Cas9 y los desafíos éticos y regulatorios que comporta”. Cuadernos de Bioética 90, 2: $223-240$.

BUCHANAN, Allen; BROCK, Dan W.; DANIELS, Norman y WIKLER, Daniel. 2002. Genética y justicia. Madrid: Cambridge University Press.

CANGUILHEM, Georges. 1986. Lo normal y lo patológico. Buenos Aires: Siglo XXI Argentina.

COMITÉ CONSULTATIF NATIONAL D’ETHIQUE POUR LES SCIENCES DE LA VIE ET DE LA SANTÉ, NUFFIELD COUNCIL ON BIOETHICS AND DEUTSCHER ETHIKRAT. 2020. Joint Statement on the Ethics of Heritable Human Genome Editing. Disponible: <https://www.nuffieldbioethics.org/assets/pdfs/Joint-statement.pdf>

COMITÉ DE BIOÉTICA DE ESPAÑA. 2019. Declaración del Comité de Bioética de España sobre la edición genómica en humanos. Disponible: $<$ http://assets.comitedebioetica.es/files/documentacion/es/CBE\%20Declaracion\%20sobre\%20 edicion\%20genomica\%20en\%20humanos.pdf>

DE LA CUESTA ARZAMENDI, José Luis. 2001. “Armas biológicas o exterminadoras e ingeniería genética: Perspectiva jurídico-penal”. En, ROMEO CASABONA, Carlos M. (Ed.). Genética y Derecho Penal. Previsiones en el Código Penal Español de 1995. BilbaoGranada: Comares.

DE MIGUEL BERIAIN, Iñigo. 2018. "Human dignity and gene editing. Using human dignity as an argument against modifying the human genome and germline is a logical fallacy”. EMBO reports, 10, 19: 1-4.

DE MIGUEL BERIAIN, Iñigo. 2019. "Modificar o no modificar el genoma de nuestra descendencia? Algunos comentarios a raíz de la Declaración del Comité de Bioética de España sobre la edición genómica en humanos”. Revista de Bioética y Derecho 47: 55-75.

DE MIGUEL BERIAIN, Iñigo y ARMAZA ARMAZA, Emilio José. 2018. “Un análisis ético de las nuevas tecnologías de edición genética: el CRISPR-Cas9 a debate”. Anales de la Cátedra Francisco Suárez 52; 179-200.

DE MIGUEL BERIAIN, Iñigo y PAYÁN ELLACURIA, Ekain. "Retos éticos y jurídicos que plantea la edición genética embrionaria a la luz del marco legal vigente en el ámbito europeo: una mirada crítica”. Anuario de Filosofía del Derecho 35: 71-92. 
DUARDO SÁNCHEZ, Aliuska. 2017. “CRISPR-Cas in Medicinal Chemistry: Applications and Regulatory Concerns”. Current Topics in Medicinal Chemistry 17: 1-8.

EMALDI CIRIÓN, Aitziber. 2001. El consejo genético y sus implicaciones jurídicas. BilbaoGranada: Comares.

EMALDI CIRIÓN, Aitziber. 2002. "Las intervenciones sobre el genoma humano y la selección de sexo (Capítulo IV)”. En, ROMEO CASABONA, Carlos M. (Ed.). 2002. El Convenio de Derechos Humanos y Biomedicina. Su entrada en vigor en el ordenamiento jurídico español. Bilbao-Granada: Comares.

EUROPEAN GROUP ON ETHICS IN SCIENCE AND NEW TECHNOLOGIES. 2016. Statement on Gene Editing. Disponible: <https://ec.europa.eu/research/ege/pdf/gene_editing_ege_statement.pdf>

EUROPEAN GROUP ON ETHICS IN SCIENCE AND NEW TECHNOLOGIES. 2018. Statement on Artificial Intelligence, Robotics and “Autonomous" Systems. Disponible: $<$ http://ec.europa.eu/research/ege/pdf/ege_ai_statement_2018.pdf>

GRACIA GUILLÉN, Diego. 2011. "Bioética”. En, Romeo Casabona, Carlos M. (Dir.). Enciclopedia de Bioderecho y Bioética. Bilbao-Granada. Cátedra Interuniversitaria Fundación BBVA - Diputación Foral de Bizkaia de Derecho y Genoma Humano y Comares.

HABERMAS, Jürgen. 2003. The Future of Human Nature. Cambridge, Massachusetts: Polity Press.

JONAS, Hans. 1997. Técnica, medicina y ética. Sobre la práctica del principio de responsabilidad. Barcelona: Paidós.

KANG, Xiangjin; HE, Wenyin; HUANG, Yuling; YU, Qian; CHEN, Yaoyong; GAO, Xingcheng; SUN, Xiaofang; FAN, Yong. 2016. "Introducing precise genetic modifications into human 3PN embryos by CRISPR/Cas-mediated genome editing”. Journal of Assisted Reproduction and Genetics 33, 5: 581-588.

LANDER, Eric Steven. 2016. “The Heroes of CRISPR”. Cell 164, 1-2: 18-28.

LANDER, Eric Steven; BAYLIS, Françoise; ZHANG, Feng; CHARPENTIER, Emmanuelle; BERG, Paul; BOURGAIN, Catherine; FRIEDRICH, Bärbel; JOUNG, J. Keith; LI, Jinsong; LIU, David; NALDINI, Luigi; NIE, Jing-Bao; QIU, Renzong; SCHOENE-SEIFERT, Bettina; SHAO, Feng; TERRY, Sharon; WEI, Wensheng; y WINNACKER, Ernst-Ludwig. 2019. “Adopt a moratorium on heritable genome editing”. Nature 567, 7747: 165-168.

JINEK, Martin; CHYLINSKI, Kryzstof; FONFARA, Ines; HAUER, Michael; DOUDNA, Jennifer Anne; y CHARPENTIER, Emmanuelle. 2012. “A Programmable Dual-RNA-Guided DNA Endonuclease in Adaptive Bacterial Immunity”. Science 337: 816-821.

MAIER, Robert; AKBARI, Ali; WEI, Xinzhu; PATTERSON, Nick; NIELSEN, Rasmus; y REICH, David. 2019. "No statistical evidence for an effect of CCR5- $\Delta 32$ on lifespan in the UK Biobank cohort”. Nature 26, 2: 178-180. 
MAX PLANCK SOCIETY. 2019. Statement on the scientific and transnational impact of genome editing and arising ethical, legal and societal issues. Disponible: <https://www.mpg.de/13509625/statement-genome-editing-englisch.pdf>

MONTOLIU, Lluís. 2019. Editando genes: recorta, pega y colorea. Las maravillosas herramientas CRISPR. Pamplona: Next Door Publishers.

MORÁN GONZÁLEZ, Luis. 2012. "Implicaciones éticas y jurídicas de las intervenciones de mejora en humanos”. En, ROMEO CASABONA, Carlos M. (Ed.). Más allá de la salud. Intervenciones de mejora en humanos. Bilbao-Granada: Comares.

NATIONAL ACADEMIES OF SCIENCES, ENGINEERING AND MEDICINE. 2017. Human Genome Editing: Science, Ethics and Governance. Washington, DC: The National Academies Press.

NATIONAL ACADEMY OF MEDICINE, NATIONAL ACADEMY OF SCIENCES, AND THE ROYAL SOCIETY. 2020. Heritable Human Genome Editing. Washington, D. C.: The National Academies Press.

NAVARRO NAVAS, Susana y CAMACHO CLAVIJO, Sandra. 2018. El ciborg humano. Granada: Comares.

REGALADO, Antonio. 2018. “Chinese scientist are creating CRISPR babies”. MIT Technology Review. Disponible: $<$ https://www.technologyreview.com/2018/11/25/138962/exclusive-chinese-scientists-arecreating-crispr-babies>

RODRIGUES, Renata de Lima. 2016. Autonomia privada e direito ao libre planejamento familiar: como as escolhas se inserem no âmbito de autodeterminação dos indivíduos na realização do projeto parental? Belo Horizonte: Pontifícia Universidade Católica de Minas Gerais.

ROMEO CASABONA, Carlos M. 1994a. "Límites penales de las manipulaciones genéticas”. El Derecho ante el Proyecto Genoma Humano 3. Madrid: Fundación BBV.

ROMEO CASABONA, Carlos M. 1994b. El Derecho y la Bioética ante los límites de la vida humana. Madrid: Centro de Estudios Ramón Areces.

ROMEO CASABONA, Carlos M. 1995. "Consideraciones jurídicas sobre las técnicas genéticas”. Anuario de Filosofía del Derecho 12: 15-38.

ROMEO CASABOnA, Carlos M. 1996a. Del Gen al Derecho. Bogotá: Universidad del Externado de Colombia.

ROMEO CASABONA, Carlos M. 1996b. “Genética y Derecho Penal: los delitos de lesiones al feto y relativos a las manipulaciones genéticas”. Derecho y Salud (DS) 1, 4: 156-179.

ROMEO CASABONA, Carlos M. 1997. “El Derecho penal ante el racismo y la eugenesia”. Eguzkilore 11 (Extraordinario): 105-135. 
ROMEO CASABONA, Carlos M. 1999a. “El Derecho ante el Proyecto Genoma Humano”. Revista Latinoamericana de Derecho Médico y Medicina Legal 4, 2: 125-140.

ROMEO CASABONA, Carlos M. (Ed.). 1999b. La eugenesia hoy. Bilbao-Granada: Comares.

ROMEO CASABONA, Carlos M. 2000a. "Bienes jurídicos implicados en la clonación”. Revista de Derecho, Criminología y Ciencias Penales 2: 145-168.

ROMEO CASABONA, Carlos M. 2000b. "El genoma humano: objeto de Derecho Internacional”. Revista de la Sociedad Internacional de Bioética (SIBI) 3: 23-45.

ROMEO CASABONA, Carlos M. (Ed.). 2002a. Los genes y sus leyes. El derecho ante el genoma humano. Bilbao-Granada: Comares.

ROMEO CASABONA, Carlos M. 2002b. "El consentimiento informado en la relación entre el médico y el paciente: Aspectos jurídicos”. En, Broggi, Marc Antoni (Ed.). Problemas prácticos del consentimiento informado 5. Barcelona: Fundació Víctor Grífols i Lucas.

ROMEO CASABONA, Carlos M. 2002c. "La genética y la biotecnología en las fronteras del derecho”. Acta Bioethica 2, 8: 283-297.

ROMEO CASABONA, Carlos M. 2002d. "El principio de no discriminación y las restricciones relativas a la realización de análisis genéticos (Capítulo IV)”. En, ROMEO CASABONA, Carlos M. (Ed.). 2002. El Convenio de Derechos Humanos y Biomedicina. Su entrada en vigor en el ordenamiento jurídico español. Bilbao-Granada: Comares.

ROMEO CASABONA, Carlos M. 2004a. "El estatuto jurídico del embrión humano”. Monografías Humanitas 4: 111-124.

ROMEO CASABONA, Carlos M. 2004b. Principio de precaución, Biotecnología y Derecho. Bilbao-Granada: Comares.

ROMEO CASABONA, Carlos M. 2007. "Hacia un Derecho transcultural para la Genética y la Biotecnología humanas”. Anuario Jurídico de La Rioja 12: 11-34.

ROMEO CASABONA, Carlos M. 2008. "La Ley de Investigación Biomédica: un nuevo mapa normativo para la investigación científica en el Sistema Nacional de Salud”. Derecho y Salud (DS) 16 (Extraordinario 2): 63-74.

ROMEO CASABONA, Carlos M. 2009. Genética, Biotecnología y Ciencias Penales. Bogotá: Pontificia Universidad Javeriana-Grupo Ed. Ibáñez.

ROMEO CASABONA, Carlos M. y DE MIGUEL BERIAIN, Iñigo. 2010. Ética de la BioTecnología. Una introducción. Granada: Comares.

ROMEO CASABONA, Carlos M. 2013. “Consideraciones jurídicas sobre los procedimientos experimentales de mejora (“enhancement”) en Neurociencias”. En, DEMETRIO CRESPO, Eduardo (Dir.) y MAROTO CALATAYUD, M. 2013. Madrid: EDISOFER. 
ROMEO CASABONA, Carlos M. 2017. "El Bioderecho y la Bioética, un largo camino en común”. Revista Iberoamericana de Bioética 3: 1-10.

ROMEO CASABONA, Carlos M.; DE MIGUEL BERIAIN, Iñigo; y DUARDO SÁNCHEZ, Aliuska. 2020. “Gene Editing From the Perspective of Spanish Law”. En, TAUPITZ, Jochen y DEURING, Silvia (Eds.). Rechtliche Aspekte der Genom-Editierung an der menschlichen Keimbahn. A Comparative Legal Study. Berlín: Springer.

SANDEL, Michael. 2015. Contra la perfección. La ética en la era de la ingeniería genética, 2. Barcelona: Marbot.

SAVULESCU, Julian y KAHANE, Guy. 2009. "The Moral Obligation to Create Children with the Best Chance of the Best Life”. Bioethics 23, 5: 274-290.

VAN DER BURG, Wibren. 1991. “The Slippery Slope Argument”. Ethics 102: 42-65.

Submissão em 09/11/2020 / Aceito em 24/11/2020 